\title{
Determination of the solid concentration in a binary mixture from pressure drop measurements
}

Sandra Turrado, José Ramón Fernández*, Juan Carlos Abanades

Spanish Research Council, INCAR-CSIC, C/ Francisco Pintado Fe, 26, 33011, Oviedo, Spain

*jramon@incar.csic.es

\section{Abstract}

A new and simple method to estimate the concentration of solids in a binary solids mixture is proposed and experimentally tested in a small fluidized bed set up. In the proposed method, it is necessary to measure the pressure drop in different sections of the bed at different gas velocities so as to be able to determine local minimum fluidization velocities using the Ergun equation. Because the minimum fluidization velocity of a solids mixture is known to be dependent on its weight fraction, a calibration curve can be derived by means of the Cheung equation and this is shown to be sufficient to obtain reasonably good estimates of the axial solids concentration profiles inside the bed. This methodology has been applied to three different mixtures of iron oxide ore of varying size with limestone or glass spheres. Satisfactory agreement between the experimental and calculated concentrations as well as pooled relative standard deviations lower than $\pm 7 \%$, are obtained in all three cases. This technique could facilitate future experimental research on solids mixing and segregation phenomena in fluidized beds, as it is a very low-cost, non-destructive and very fast method to determine solids concentration bed profiles.

Keywords: Fluidization; mixing; segregation; solids concentration; calibration 


\section{Introduction}

Fluidized-bed reactors containing solids mixtures are widely used in many industrial processes, such as, the chemical, food and pharmaceutical industries, as well as, in power plants and gas purification systems [1-3]. The presence of solids with different characteristics (i.e., size, density and/or shape) makes the hydrodynamic behaviour of these systems more complex to predict $[4,5]$. Mixing and segregation phenomena may coexist during fluidization, giving rise to non-homogeneous solids distributions in axial and radial directions. In binary mixtures, the denser (and/or larger) particles (typically called jetsam) tend to fall to the bottom of the bed, while the lighter (and/or smaller) solids (usually referred to as flotsam) migrate to the top [6, 7]. A knowledge of local solids concentrations therefore is important for the design of the reactors and for the operation and optimization of the plants [8]. Also, models for the mixing and segregation of the solids in fluidized beds still require a substantial input of experimental information for validation purposes. Therefore, the accurate measurement of the concentration of solids in different parts of the fluidized bed is essential. Sampling or extraction of selected sections of the bed is perhaps the simplest and lowest cost method when investigating solids segregation in fluidized beds. This consists in taking samples from different points of the fluidized bed using a suction probe $[9,10]$. The solids are subsequently sieved (or separated by other mechanical procedures) and weighed to obtain the local concentrations. However, this is a tedious, time-consuming, and highly intrusive measurement technique $[11,12]$.

Numerous techniques have been reported in the literature for quantifying the local concentrations of solids in fluidized beds, although only a few of them are suitable for binary mixtures $[1,8,13-15]$. There are sophisticated methods used not only to measure local solids volume concentrations, but also to accurately determine the axial and radial distribution of solids inside the bed in dynamic conditions, as well as solids mass flow profiles. Tomography methods are used to obtain images per section using X-ray radiation [16], magnetic resonance [17] or by measuring the electrical 
capacitance of the solids in motion [18]. These methods use a rotating sensor or several sensors arranged around the studied plane and the linear algorithms obtained allow a cross-sectional image of the plane to be reconstructed [19]. These techniques that have been applied to the study of the mixing and segregation of binary mixtures have been demonstrated to have a good penetration capability [14]. However, tomography techniques are generally complex and expensive, and their accuracy depends to a great extent on the sensitivity of the sensors [14, 15]. Attenuation and scattering methods based on x-rays, gamma-rays or sound waves are another alternative for measuring the spatial distribution of solids via the detection of changes in the absorption of radiation or the noises generated by particle collisions $[1,20]$. These techniques are readily applicable in a wide range of experimental conditions, but in many cases they are expensive due to the complexity of the sensor and the need for protection against the radiation [14, 15]. Capacitance measurement techniques can be used to obtain the concentration of solids by means of several electrodes that register the changes in the dielectric constant of the phase present between the electrodes [21, 22]. Electrostatic probes, on the other hand, measure the electrical charge acquired by the particles during fluidization when they impact against the walls [23]. Both capacitance and electrostatic probes are generally inexpensive and simple to implement but too sensitive to moisture content and particle size [14].

When the solids have different visual characteristics and the experiments can be carried out in transparent wall apparatus, digital imaging analysis can be used to study solids circulation patterns and to calculate extensive or local properties in fluidized beds [24-27]. This is a non-intrusive visualization method in which physical flow disturbances (typically created by intrusive probes) are avoided [28, 29]. Images are taken by high-speed digital cameras and specific software is used for image acquisition, data processing and analysis. The local concentrations of solids can be directly obtained from an analysis of image properties (i.e., when the particles are sufficiently large to be identified in the image) [30] or by means of calibration procedures in which the concentration is related to pixel luminance [31, 32]. 
In this work, a simple non-destructive procedure is proposed to calculate the concentration of solids in binary mixtures in fluidized beds from the measurement of the pressure drop at different sections along the bed. Below, we outline the principles underlying the method and describe the experiments carried out for its validation.

\section{Method}

The method proposed for calculating the concentration of solids in a binary mixture is based on the empirical correlation (Eq. 1) reported by Cheung et al. [33], which shows the dependence of the minimum fluidization velocity of the mixture $\left(u_{m f}\right)$ on the minimum fluidization velocity of the pure components $\left(u_{p}\right.$ and $\left.u_{f}\right)$ and the weight fraction of the solids in the bed $\left(x_{p}, x_{f}=1-x_{p}\right)$.

$u_{m f}=u_{f}\left(\frac{u_{p}}{u_{f}}\right)^{x_{p} b}$

where the subscript $p$ refers to the component with the highest minimum fluidization velocity, $f$ refers to the component with the lowest minimum fluidization velocity and the parameter $b$ is $a$ constant value $(b=2)$ in the original equation [33]. However, in the procedure proposed here, $\mathrm{b}$ is considered an adjustable parameter which depends on the characteristics of the solids mixture and it should therefore be determined by calibration.

In order to use equation (1), it is first necessary to calculate the minimum fluidization velocities of the individual components, $u_{p}$ and $u_{f}$. A standard procedure [34] is followed, where the pressure drops measured at different points of the bed are recorded at increasing gas velocities. After that, the minimum fluidization velocity can easily be calculated by means of the Ergun equation [35], which for a laminar regime is as follows:

$\left(\frac{\Delta p}{L}\right)_{\max }=\left(150 \frac{\left(1-\epsilon_{m f}\right)^{2}}{\epsilon_{m f}^{3}} \frac{\mu}{\left(\phi_{s} d_{p}\right)^{2}}\right) u_{m f}$ 
where $d_{p}$ is the average particle diameter, $\mu$ is the gas viscosity, $\phi_{s}$ represents the particle sphericity and $\epsilon_{m f}$ the bed porosity for the conditions of minimum fluidization. The value of the maximum pressure drop of the bed (i.e., the value represented by a bold black line in Fig. $2 a$ and Fig. $2 b$ ) is obtained according to equation 3:

$$
\left(\frac{\Delta p}{L}\right)_{\max }=\frac{M_{s} g}{A_{\text {column }} L}
$$

where $M_{s}$ is the mass of the solids mixture, $A_{\text {column }}$ and $L$ are the cross section area and the length of the bed, respectively, and $\mathrm{g}$ is the gravitational acceleration.

The basis of the method for deriving the solids concentration is to obtain experimentally the local values of minimum fluidization velocity, which can also be inferred from the $\Delta \mathrm{P}$ measurements at different superficial gas velocities in the defluidized bed following the Ergun equation (Eq. 2). In other words, if different values of $u_{m f}$ can be experimentally detected in a solids mixture, this will be a clear indication that different concentrations of solids are present in such mixtures. The solids concentration can then be obtained from a calibration curve based on equation 1 (Eq. 4):

$\ln \left(u_{m f}\right)=\ln \left(\frac{u_{p}}{u_{f}}\right) x_{p}{ }^{b}+\ln \left(u_{f}\right)$

In the next section, we illustrate the application of this technique to mixtures of different-sized iron oxide ore, limestone and glass spheres, which are currently being investigated in our group as functional materials in new combined chemical looping systems for $\mathrm{CO}_{2}$ capture [36-38].

\section{Experimental}

The experiments for measuring the concentration of binary mixtures of solids were carried out using a methacrylate column with an inner diameter of $0.042 \mathrm{~m}$ and a height of $1 \mathrm{~m}$, equipped with 10 pressure taps equally spaced along the column at intervals of $0.03 \mathrm{~m}$ (Fig. ). Nine $\Delta \mathrm{P}$ are then measured at different axial positions, which allows up to 9 values of $u_{m f}$ to be calculated along the 
bed. The air flow needed to fluidize the solids (between 0.2 and $5 \mathrm{Nl} / \mathrm{min}$ depending on the experiment) was regulated by a mass flow controller. The signals obtained by the pressure sensors were recorded on a computer by means of a data logger. Schematic diagrams of the experimental setup and of the procedure for the calculation of the solids concentration are shown in Fig. 1.

Iron oxide ore, limestone and glass spheres with different particle sizes were used to obtain binary mixtures with compositions varying from $0 \mathrm{wt} . \%$ to $100 \mathrm{wt} . \%$. The individual properties of the solids used are listed in Table 1. Both iron ore and limestone behave like solids of the Geldart Group B, while the glass spheres fluidize like solids of the Geldart Group A. The total mass of solids introduced into the fluidized bed varied between 250 and $800 \mathrm{~g}$ depending on the test. The experiments were carried out at room temperature and at atmospheric pressure.

In a typical calibration experiment, a binary mixture with known proportions of each material is introduced into the column. The solids are then subjected to intense fluidization for a few minutes (at gas velocities 5-10 times higher than the $u_{m f}$ of the jetsam) in order to reach perfect mixture. Afterwards, the air flow is abruptly cut off, obtaining a mixed solids bed ready for the subsequent determination of the minimum fluidization velocity $\left(\mathrm{u}_{\mathrm{mf}}\right)$. With this procedure, both bed compaction and solids segregation should be avoided. It is well known that the initial mixing of the bed greatly affects the pressure drop vs. the gas velocity curve [39]. If the bed is compacted, the $u_{m f}$ calculated using the Ergun equation will be slightly lower than the true value. There will be fewer voids through the gas can flow along the column, and consequently, the variation of the pressure drop with gas velocity will be greater than expected before the point of incipient fluidization is reached. These unavoidable phenomena highlight the need to calibrate first the Cheung equation (Eqs. (1) and (4)) for the special characteristics of the solids and the experimental set-up by running experiments with known concentrations and well-mixed solids mixtures. With this procedure, the local values of $u_{m f}$ at a similar level of bed compaction is experimentally obtained, which minimizes possible errors in the application of the Ergun equation. 
Once the calibration exercises have been performed and the bed has been defluidized, different flow rates below that of incipient fluidization are used to obtain sufficient pressure drop data for calculating the $u_{m f}$ of the binary mixture. The availability of 10 pressure measurement points at different heights along the column allows 9 independent experimental Ergun plots to be obtained from differential pressure measurements (plus one more from the measurement of the absolute pressure which should equal the sum of the previous measurements). Ideally, if the solids are perfectly mixed, all the Ergun plots should be identical. However, in practice, the perfect mixing of the solids is difficult to achieve and a certain amount of segregation occurs during the defluidization of the bed, which generates some mismatches in the pressure measurements, as explained below. This measurement procedure should be repeated several times for the entire range of concentrations in order to collect sufficient data on the variation of $u_{m f}$ with the changing composition of the binary mixtures (i. e., up to $9 u_{m f}$ values per experiment). Finally, an empirical correlation is obtained by applying least square adjustment to Eq. (1). Moreover, the average $u_{m f}$ of the mixture and the standard deviation of the individual measurements at different axial positions are calculated, as explained below.

\section{Results and discussion}

As an example of the experimental results, Fig. 2a represents the calculation of the $u_{m f}$ for a mixture composed of $30 \mathrm{wt} . \%$ of glass spheres (with a $d_{p}$ of $70-110 \mu \mathrm{m}$ ) and $70 \mathrm{wt} . \%$ of iron oxide particles (with a $d_{p}$ of $200-250 \mu \mathrm{m}$ ), which has been perfectly mixed by feeding in an air flow of $0.22 \mathrm{~m} / \mathrm{s}$. As can be seen from the figure, the pressure drop increases with the gas velocity, following a linear trend up to a maximum value that corresponds to the state of complete fluidization of the solids (Eq. 3). The pressure drop is recorded at eight different heights and 7 different values of $\Delta \mathrm{P}$ are obtained (numbered from 3 to 9 in the legend of Fig. 2). The dots obtained at the same bed slices are connected by grey lines, whose slope corresponds to the term in large brackets on the right-hand side of Eq. (2). If the solids have been uniformly distributed along the bed, all the grey lines should 
have the same slope. However, it can be seen that the slopes diverge slightly due to a certain degree of segregation in the column, where the finer glass spheres tend to float, while the coarse iron oxide particles move downwards during fluidization. The objective of the calibration procedure discussed below is to determine the calibration Eq. (4) necessary to obtain the solids concentration profile from a simple set of $\Delta \mathrm{P}$ measurements. For the purpose of comparison, Fig. $2 \mathrm{~b}$ includes the same experiment carried out on a partially-segregated bed. The resulting bed is obtained by fluidizing the same solids at a lower velocity of $0.09 \mathrm{~m} / \mathrm{s}$. As can be seen, three values of local $\mathrm{u}_{\mathrm{mf}}$ are observed depending on the local concentration of the solids in the different bed slices between the pressure taps. The lowest $u_{m f}$ value $(0.012 \mathrm{~m} / \mathrm{s})$ corresponds to the upper part of the bed (i.e., from points 3 to 5), where particles of flotsam and jetsam coexist $\left(x_{p}=0.48\right)$, while the highest value of $u_{m f}(0.053$ $\mathrm{m} / \mathrm{s}$ ) corresponds to the lower part of the bed (i.e., from points 7 to 9 ), where the material is mainly jetsam $\left(x_{p}=0.94\right)$. Finally, an intermediate value of $u_{m f}(0.016 \mathrm{~m} / \mathrm{s})$ is obtained for the interface formed between the two segregated phases (i.e, point 6) $\left(x_{p}=0.62\right)$.

The variation of the minimum fluidization velocity for different compositions of several solids mixtures (see Table 1) has been adjusted to the equation formulated by Cheung et al. (Eq. 3). Fig. 3 shows the calibration curves obtained from the experimental data of the three mixtures studied in this work (see Table 2).

Mixture I is composed of $400-600 \mu \mathrm{m}$ limestone and $200-250 \mu \mathrm{m}$ iron oxide ore. A value for the exponent $b$ of 1.93 is calculated so that the experimental results can be fitted using the Cheung equation. In the case of mixture II (composed of 355-400 $\mu \mathrm{m}$ iron oxide ore and 70-110 $\mu \mathrm{m}$ glass spheres), the experimental data are accurately fitted using a modified Cheung equation with a value of 3 for the parameter b. For mixture III (composed of 200-250 $\mu \mathrm{m}$ iron oxide and 70-110 $\mu \mathrm{m}$ glass spheres), the variation of the minimum fluidization velocity with increasing amounts of jetsam cannot be accurately described by using a constant value for the parameter $b$ in the Cheung equation. In this case, the Cheung equation fits the experimental results better if the parameter $b$ is 
included as a function of the weight fraction of the jetsam (Eq. 5). Two additional parameters $\left(\mathrm{b}_{0}\right.$ and a) then need to be fitted to the modified Cheung equation (i.e., $b_{0}=1.878, a=0.791$ in this particular case).

$b=b_{0}+a x_{p}$

It should be noted that these adjustments to the Cheung equation are required to improve the quality of the calibration fit of a specific mixture in the specific experimental protocol used in this work during the experiments. The need to modify the exponent $b$ for some solid mixtures (especially for those with the largest differences in particle properties) is likely to arise from the deviation of the bed from the ideal loose state that is needed to achieve an accurate determination of $u_{m f}$ from the $\Delta \mathrm{P}$ measurements [34]. In other words, we are not questioning the suitability of the parameter $\mathrm{b}=2$ for these mixtures, but simply the use of the Cheung equation as a basis for the specific calibration of the mixture investigated.

The standard deviation (SD) and the relative standard deviation (RSD) have been calculated for each set of experiments carried out using the same weight fraction. In these experiments the RSD is the ratio between the standard deviation and the average minimum fluidization velocity $\left(\overline{u_{m f}}\right)$ calculated for a determined solids mixture. This allows the dispersion of the experimental results to be evaluated for every binary mixture tested.

$\overline{u_{m f(l)}}=\frac{1}{n_{i}} \sum_{j=1}^{n_{i}} u_{m f(i, j)}$

$S D_{i}=\sqrt{\frac{1}{n_{i}-1} \sum_{j=1}^{n_{i}}\left(u_{m f(i, j)}-\overline{u_{m f(l)}}\right)^{2}}$

$R S D_{i}=\frac{S D_{i}}{\overline{u_{m f(l)}}} \times 100$ 
Finally, the calculation of the pooled relative standard deviation obtained from the individual RDS (Eq. 9) indicates how well the proposed method explains the experimental data.

$$
R S D_{\text {pooled }}=\sqrt{\frac{\sum_{i=1}^{k}\left(n_{i}-1\right) R S D_{i}{ }^{2}}{\sum_{i=1}^{k} n_{i}-1}}
$$

The individual relative standard deviations (RSD) calculated for the three mixtures studied are shown in Fig. 4. In the three cases, values of RSD lower than $10 \%$ are obtained. Moreover, the pooled relative standard deviation ( $\mathrm{RSD}_{\text {pooled }}$ ) has been calculated for the three mixtures, and values lower than $\pm 6.9 \%$ (see Table 2), which close to the value originally obtained by Cheung et al. [33], were obtained.

Additional experiments were carried out with known mixtures of solids in order to confirm the reliability of the proposed methodology when determining the composition of the bed from experimental $u_{m f}$ values. Both the experimental and calculated weight fractions of the experiments carried out with the three mixtures are represented in Fig. 5. Correlation coefficients of above 0.93 have been calculated in the three cases, which demonstrates that the modified Cheung equation predicts the composition of these mixtures reasonably well.

A summary of the main calibration results obtained in this work for the three mixtures studied is presented in Table 2. For every binary mixture, the pooled relative standard deviations are lower than $\pm 7 \%$, which demonstrates the consistency of the proposed method. Moreover, the values calculated for the parameter $b$ in each case are close to that obtained originally by Cheung et al. [33] (i.e., 2). However, in binary mixtures where the solids behave either as jetsam or as flotsam depending on bed composition [4], as in the case of mixture I, the proposed technique shows a higher dispersion in the experimental data (i.e., a higher $\mathrm{RSD}_{\text {pooled }}$ value) and the determination of the solids bed composition is less accurate. On the other hand, some dispersion in the experimental 
data is unavoidable, since a perfect mixing of the solids is not possible and some segregation and a certain degree of bed compaction also occur at the lowest gas velocities tested. However, these fluctuations during the tests can be considered as systematic and they can be accounted for by adjusting the calibration curves.

In light of these results, the method proposed seems to be especially suitable for mixtures where the solids exhibit very different minimum fluidization velocities (i.e., $u_{p} / u_{f}$ ratios $>2$ ) caused by differences in density and/or particle diameter. The correlation coefficient and the pooled relative standard deviation obtained for these solids are satisfactory, confirming the suitability of the method for this kind of mixture. Regarding the difference in the particle size between the fine and the coarse particles present in a mixture, Cheung et al. restricted the use of their empirical equation for mixtures with $d_{s} / d_{b}$ ratios higher than 0.3 (where $d_{s}$ and $d_{b}$ are the particle diameter of the fine and the coarse solid, respectively). However, the calibration method presented in this work has shown to be valid for mixtures with lower $d_{s} / d_{b}$, as it is the case of mixture II composed of iron oxide and glass spheres with $d_{s} / d_{b}$ of around 0.2 .

\section{Acknowledgements}

The authors acknowledge the financial support received from the Spanish Ministry of Economy, Industry and Competitivity (ENE2015-68885-C2-1-R).

\section{Conclusions}

A new simple, non-intrusive and low-cost procedure based on pressure drop measurements has been shown to be suitable for determining the axial solids concentration profile in binary mixtures. It is based on the possibility of correlating the minimum fluidization velocity of the mixture with the solid concentration by means of the Cheung equation (Eq. 1). The minimum fluidization velocity is obtained from pressure drop measurements following the standard procedure based on the Ergun 
equation (Eq. 2). Parameter $b$ in the Cheung equation has been adjusted and even redefined (Eq. 5) when necessary in order to obtain the optimum correlation for each case.

The method has been validated by applying it to three different mixtures of iron oxide ore of different particle diameter with limestone or glass spheres. A satisfactory agreement between the experimental and calculated concentrations as well as pooled relative standard deviations lower than $\pm 7 \%$ have been obtained, confirming the consistency of the method. Furthermore, the RSD $\mathrm{pooled}$ values obtained are congruent with the work of Cheung et al.

\section{References}

[1] J. J. Nieuwland, R. Meijer, J.A.M. Kuipers, W.P.M. van Swaaij, Measurements of solids concentration and axial solids velocity in gas-solid two-phase flow, Powder Technol. 87(2) (1996) 127-139.

[2] B. Leckner, Fluidized bed combustion: Mixing and pollutant limitation, Prog. Energ. Combust. Sci. 24(1) (1998) 31-61.

[3] T.F. Wall, Combustion processes for carbon capture, P. Combust. Inst. 31(1) (2007) 31-47.

[4] S. Chiba, A.W. Nienow, T. Chiba, H. Kobayashi, Fluidised binary mixtures in which the denser component may be flotsam, Powder Technol. 26(1) (1980) 1-10.

[5] N.S. Naimer, T. Chiba, A.W. Nienow, Parameter estimation for a solids mixing/segregation model for gas fluidised beds, Chem. Eng. Sci. 37(7) (1982) 1047-1057.

[6] P. N. Rowe, A.W. Nienow, A.J. Agbim, The Mechanisms by which particles segregate in gas fluidised beds-binary systems of near-spherical particles, Trans. Inst. Chem. Eng. 50(4) (1972) 310.

[7] A.W. Nienow, P. N. Rowe, L.Y.L. Cheung, A quantitative analysis of the mixing of two segregating powders of different density in a gas-fluidised bed. Powder Technol. 20(1) (1978) 89-97. 
[8] J. Werther, Measurement techniques in fluidized beds. Powder Technol. 102(1) (1999) 15-36.

[9] J.C. Abanades, S. Kelly, G.P. Reed, A mathematical model for segregation of limestone-coal mixtures in slugging fluidised beds, Chem. Eng. Sci. 49 (1994) 3943-3953.

[10] Y. Zhang, B. Jin, W. Zhong, Experimental investigation on mixing and segregation behavior of biomass particle in fluidized bed, Chem. Eng. Proces. 48 (2009) 745-754.

[11] A. Marzocchella, et al., Transient fluidization and segregation of binary mixtures of particles, AIChE J. 46(11) (2000) 2175-2182.

[12] B. Jin, et al., Experimental Study of the Effect of Particle Density on Mixing Behavior in a SpoutFluid Bed, Ind. Eng. Chem. Res. 48(22) (2009) 10055-10064.

[13] J.G. Yates, S.J.R. Simons, Experimental methods in fluidization research. Int. J. Multiphas. Flow 20 (1994) 297-330.

[14] Y. Zheng, Q. Liu, Review of techniques for the mass flow rate measurement of pneumatically conveyed solids. Measurement 44(4) (2011) 589-604.

[15] Y. Yong, Mass flow measurement of bulk solids in pneumatic pipelines. Meas. Sci. Technol. 7(12) (1996) 1687.

[16] W. Bai, N.K.G. Keller, T. J. Heindel, R. O. Fox, Numerical study of mixing and segregation in a biomass fluidized bed. Powder Technol. 237 (2013) 355-366.

[17] N. Sommier, P. Porion, P. Evesque, B. Leclerc, P. Tchreloff, G. Couarraze, Magnetic resonance imaging investigation of the mixing-segregation process in a pharmaceutical blender. Int. J. Pharm. $222(2001)$ 243-258.

[18] C. Rautenbach, Possible identification of size difference segregation using electrical capacitance tomography and statistical analysis. Eur. J. Sci. Res. 116(3) (2013) 351-364. 
[19] R.A. Williams, C.G. Xie, Tomographic Techniques for Characterising Particulate Processes, Part. Part. Syst. Char. 10(5) (1993) 252-261.

[20] Y.C. Seo, D. Gidaspow, An x-ray-.gamma.-ray method of measurement of binary solids concentrations and voids in fluidized beds, Ind. Eng. Chem. Res. 26 (1987) 1622-1628.

[21] M. Richtberg, R. Richter, K.E. Wirth, Characterization of the flow patterns in a pressurized circulating fluidized bed, Powder Technol. 155 (2005) 145-152

[22] J. Huang, Y. Lu, H. Wang, A new quantitative measurement method for mixing and segregation of binary-mixture fluidized bed by capacitance probe, Chem. Eng. J. 326 (2017) 99-108.

[23] G.E. Klinzing, A. Zaltash, C.A. Myler, Particle velocity measurements through electrostatic field fluctuations using external probes, Part. Sci. Technol. 5 (1987) 95-104.

[24] K.S Lim, P.K. Agarwal, B.K. O’Neill, Measurement and modelling of bubble parameters in a twodimensional gas-fluidized bed using image analysis, Powder Technol. 60 (1990) 159-171.

[25] K.S. Lim, V.S. Gururajan, P.K. Agarwal, Mixing of homogeneous solids in bubbling fluidized beds: Theoretical modelling and experimental investigation using digital image analysis, Chem. Eng. Sci. 18 (1993) 2251-2265.

[26] C. Wightman, F.J. Muzzio, J. Wilder, A quantitative image analysis method for characterizing mixtures of granular materials, Powder Technol. 89 (1996) 165-176.

[27] J. Yang, J. Zhu, A novel method based on image processing to visualize clusters in a rectangular circulating fluidized bed riser, Powder Technol. 254 (2014) 407-415.

[28] M.J.V. Goldschmidt, J.M. Link, S. Mellema, J.A.M. Kuipers, Digital image analysis measurements of bed expansion and segregation dynamics in dense gas-fluidised beds, Powder Technol. 138 (2003) 135-159. 
[29] J. Link, C. Zeilstra, N. Deen, H. Kuipers, Validation of a discrete particle model in a 2D spout-fluid bed using non-intrusive optical measuring techniques, Canadian J. Chem. Eng. 82 (2004) 30-36.

[30] Y. Shan, M.D. Normand, M. Peleg, Estimation of the surface concentration of adhered particles by color imaging, Powder Technol. 92 (1997) 147-153.

[31] G. Grasa, J.C. Abanades, A calibration procedure to obtain solid concentrations from digital images of bulk powders, Powder Technol. 114 (2001) 125-128.

[32] J. Yang, J. Zhu, Visualization of solids phase separation in a rectangular CFB riser using a novel image calibration method, Powder Technol. 273 (2015) 76-82).

[33] L.Y.L. Cheung, A.W. Nienow, and P.N. Rowe, Minimum fluidisation velocity of a binary mixture of different sized particles, Chem. Eng. Sci. 29 (1974) 1301-1303.

[34] D. Kunii, O. Levenspiel, Fluidization engineering. 1969: Wiley.

[35] S. Ergun, Fluid Flow Through Packed Columns, Chem. Eng. Progress 48 (1952) 89-94.

[36] J.R. Fernández, J.C. Abanades, $\mathrm{CO}_{2}$ capture from the calcination of $\mathrm{CaCO}_{3}$ using iron oxide as heat carrier, J Clean Prod. 112 (2016) 1211-1217.

[37] J.R. Fernández, J.C. Abanades, Sorption enhanced reforming of methane combined with an iron oxide chemical loop for the production of hydrogen with $\mathrm{CO}_{2}$ capture: Conceptual design and operation strategy. Appl. Therm. Eng. 125 (2017) 811-822.

[38] J.R. Fernandez, I. Martinez, J.C. Abanades, M.C. Romano, Conceptual design of a Ca-Cu chemical looping process for hydrogen production in integrated steelworks. Int. J. Hydrog. Energ. 42 (2017) $11023-11037$.

[39] K. Noda, S. Uchida, T. Makino, H. Kamo, Minimum fluidization velocity of binary mixture of particles with large size ratio, Powder Technol. 46 (1986) 149-154. 


\section{List of symbols}

a coefficient of modified Cheung equation

$A_{\text {column }}$ cross section area of the column $\left(\mathrm{m}^{2}\right)$

b coefficient of Cheung equation

$b_{0}$ coefficient of modified Cheung equation

$d_{p}$ particle diameter $(m)$

g gravitational acceleration $\left(9.81 \mathrm{~m} / \mathrm{s}^{2}\right)$

$\mathrm{L}$ bed length $(\mathrm{m})$

$\mathrm{M}_{\mathrm{s}}$ total mass of the solids mixture $(\mathrm{kg})$

$\mathrm{n}$ number of measurements of minimum fluidization velocity for each weight fraction (-)

SD standard deviation $(\mathrm{m} / \mathrm{s})$

RSD relative standard deviation (-)

$\mathrm{RSD}_{\text {pooled }}$ pooled relative standard deviation (-)

$\mathrm{u}_{0}$ gas velocity $(\mathrm{m} / \mathrm{s})$

$\mathrm{u}_{\mathrm{f}}$ minimum fluidization velocity of the component with lower minimum fluidization velocity $(\mathrm{m} / \mathrm{s})$

$\mathrm{u}_{\mathrm{mf}}$ minimum fluidization velocity $(\mathrm{m} / \mathrm{s})$

$\mathrm{u}_{\mathrm{p}}$ minimum fluidization velocity of the component with higher minimum fluidization velocity $(\mathrm{m} / \mathrm{s})$

$x_{p}$ mass fraction of the component with higher minimum fluidization velocity

Greek letters 
$\Delta \mathrm{P}$ bed pressure drop $(\mathrm{Pa})$

$\mu$ gas viscosity $(\mathrm{kg} / \mathrm{m} \cdot \mathrm{s})$

$\phi_{\mathrm{s}}$ particle sphericity

$\rho$ density $\left(\mathrm{kg} / \mathrm{m}^{3}\right)$

$\epsilon_{\mathrm{mf}}$ minimum fluidization porosity

\section{Figure captions}

Fig. 1. Schematic diagrams of the experimental setup and of the procedure for the calculation of the solids concentration.

Fig. 2. Determination of the minimum fluidization velocity of a mixture composed of 70 wt.\% $\mathrm{Fe}_{2} \mathrm{O}_{3}$ ( $d_{p}$ between $200-250 \mu \mathrm{m}$ ) and 30 wt.\% glass spheres (with a $d_{p}$ of $70-110 \mu \mathrm{m}$ ) from pressure drop 
measurements taken at 7 different heights. a) well-mixed solids, b) a partially-segregated bed of solids ( $u_{f}$ refers to flotsam and $u_{p}$ to jetsam).

Fig. 1. Variation of the minimum fluidization velocity of the solids mixtures with increasing amounts of jetsam $\left(\mathrm{x}_{\mathrm{p}}\right)$. Mixture I is composed of 400-600 $\mu \mathrm{m}$ limestone and 200-250 $\mu \mathrm{m}$ iron oxide ore; mixture II is composed of $355-400 \mu \mathrm{m}$ iron oxide and $70-110 \mu \mathrm{m}$ glass spheres; mixture III is composed of $200-250 \mu \mathrm{m}$ iron oxide and $70-110 \mu \mathrm{m}$ glass spheres.

Fig 4. Variation of the relative standard deviations with the concentration of jetsam for the mixtures studied.

Fig. 5. Comparison of the experimental concentrations with those calculated using the Cheung equation for the mixtures studied.
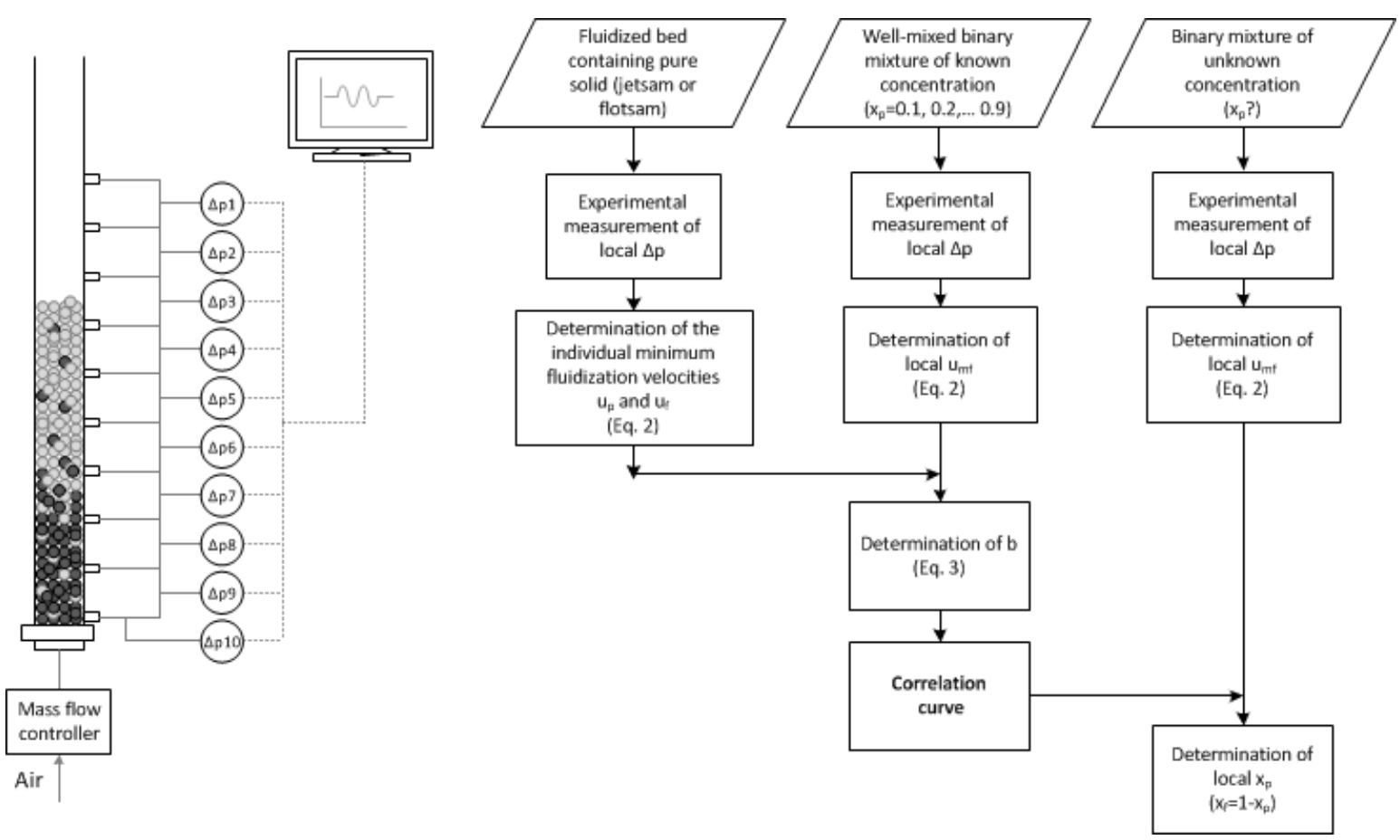

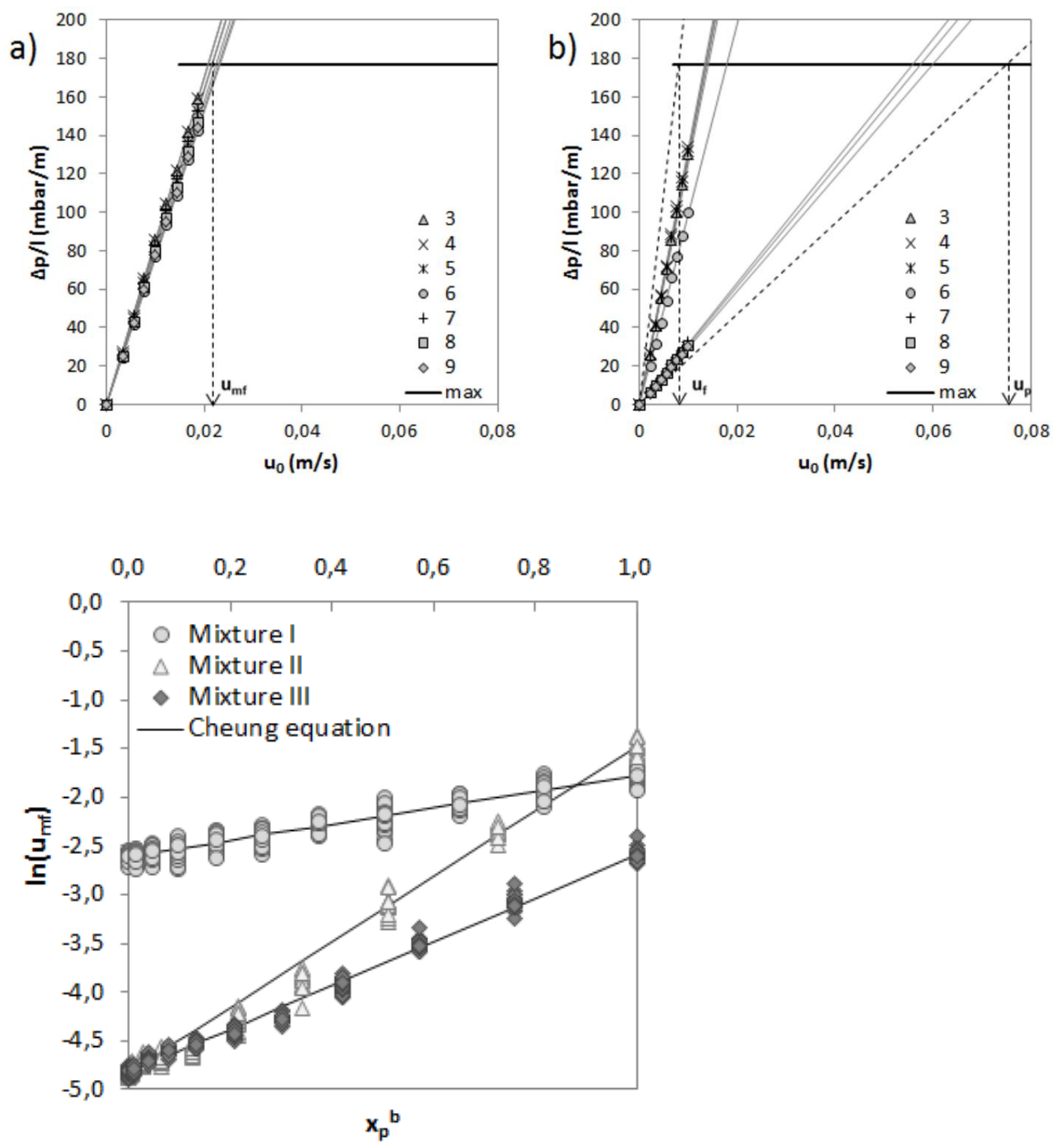

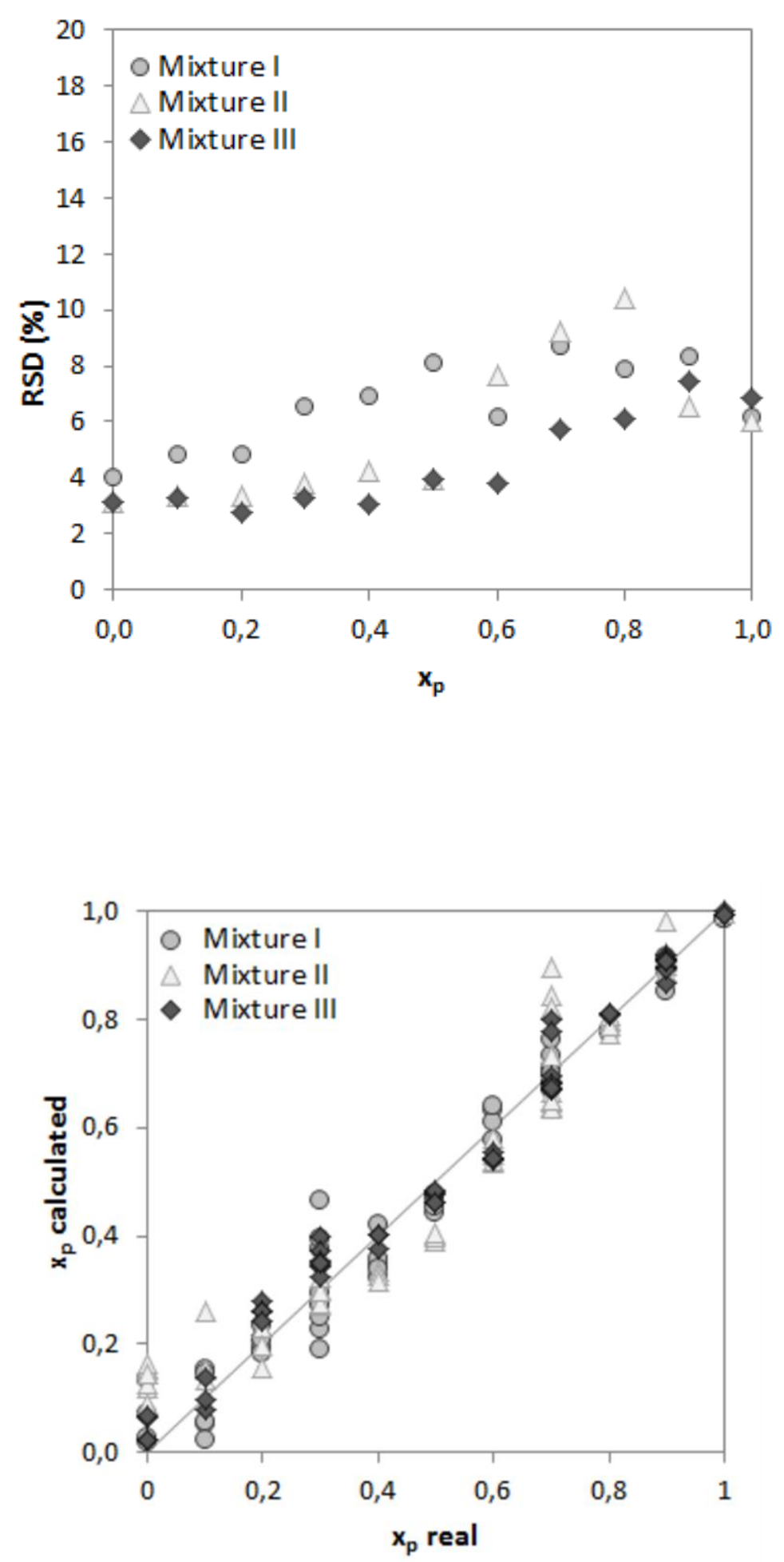